\title{
Addressing rising alcohol-related harms in Canada
}

\author{
Sheryl Spithoff MD MSc
}

Cite as: CMAJ 2019 July 22;191:E802-3. doi: 10.1503/cmaj.190818

See related article at www.cmaj.ca/lookup/doi/10.1503/cmaj.181575

$\mathbf{N}$

ew data confirm that alcohol-related harms are on the rise in Canada. Linked research shows that, between 2003 and 2016, the rate of alcohol-related emergency department visits in Ontario increased 4.4 times more than the increase of visits overall. ${ }^{1}$ Although the absolute number of visits remained greater among men, the rate of increase was higher among women $(86.5 \%$ v. $53.2 \%)$. Visits by young women increased by $240 \%$. Accumulating evidence suggests that Canadians should be prepared for further increases in alcohol-related harms, particularly in young women and girls.

The linked study's findings align with data from the Canadian Institute for Health Information showing that alcohol-related deaths increased by $26 \%$ for women and by $5 \%$ for men between 2001 and 2016-2017. Furthermore, alcohol-related hospital admissions increased by $3 \%$ among women in just 1 year, from 2015-2016 to 2016-2017. In 2016-2017, hospital admissions for girls aged 10-19 years outnumbered hospital admissions for boys of the same age (www.cihi.ca/en/alcohol-harm-on-the-rise -for-canadian-women).

According to a report from Canada's Chief Public Health Officer, alcohol-related harms include suicide, injuries, pancreatitis, liver disease, anxiety disorders, brain damage and death. ${ }^{2}$ Experts estimate that alcohol is as harmful to the individual user as cocaine. ${ }^{3}$ Alcohol also has a devastating impact at the societal level. In 2014, alcohol use by Canadians caused 14827 deaths and cost the public $\$ 14.6$ billion, with direct health care costs contributing $\$ 11.1$ billion. $^{4}$

These harms appear to be associated with sociocultural trends. Statistics Canada reports a gradual increase in annual alcohol consumption per person since the late 1990s, from $7.5 \mathrm{~L}$ per person in 1999 to $8.1 \mathrm{~L}$ in 2017 (www.uvic.ca/research/centres /cisur/stats/alcohol/index.php). Consumption at the population level is closely linked to harms and may account for some of the observed national increase in harms. ${ }^{2}$ However, in Ontario, consumption of alcohol remained relatively stable from 2003 to 2016, indicating that there are other factors contributing to the observed increased rates of emergency department visits (www150.statcan.gc.ca/t1/tbl1/en/tv.action?pid=1010001001).

\section{KEY POINTS}

- Recent evidence shows that alcohol-related harms in Ontario and across Canada are on the rise.

- Young women and girls have experienced a dramatic increase in harms.

- Policy changes in Ontario to increase alcohol availability and to reduce price minimums are likely to lead to further alcoholrelated harms and costs.

- A concerted, system-wide, public health approach - that takes gender into consideration - could lead to reduction in alcohol use, related harms and costs.

Canadian women consume more alcohol now than they did a few decades ago..$^{5,6}$ This appears to be part of a larger global trend, reflecting changing gender norms around substance use. ${ }^{7,8}$ Not only are Canadian women drinking more, they are also consuming alcohol in more harmful patterns. ${ }^{5,6}$ Given that women are more vulnerable to the effects of alcohol, it is unsurprising that women have experienced a greater increase in alcohol-related harms than men in Ontario and Canada (www.cihi.ca/en/alcohol -harm-in-canada). ${ }^{1}$ Young women are most affected, likely as the result of having the largest increases in consumption: in the youngest birth cohorts, women have reached parity with men for alcohol consumption globally. ${ }^{7}$ Youth are also more likely to experience negative effects from alcohol use than adults. ${ }^{2}$

Research has shown that some public policies can reduce alcohol consumption and alcohol-related harms. Increasing prices for alcoholic beverages - through taxation or price minimums - is one of the most effective mechanisms, particularly for younger drinkers and heavy drinkers. ${ }^{2,9}$ An analysis in Ontario and British Columbia found that setting a minimum price of $\$ 1.50$ per drink was likely to save 131 and 56 lives, respectively, per year by 10 years after implementation. ${ }^{10}$ Further price increases saved more lives in the analysis. Price minimums and increased taxation have the additional benefit of increasing tax revenues. ${ }^{9}$ Government ownership of retail 
outlets and limits on alcohol availability (hours of operation and outlet density) are other effective strategies endorsed by the World Health Organization. ${ }^{2,11}$

Although the evidence is less clear, banning promotion of alcohol would likely reduce harm, particularly among youth. ${ }^{2}$ Recent targeted promotional activities appear to have contributed to increased consumption by women. ${ }^{8}$ More broadly, social programs that reduce economic disparity and poverty are also likely to reduce harms. ${ }^{11}$ Even when rates of alcohol consumption are similar, people with higher socioeconomic status are far less likely to experience alcohol-related harms. ${ }^{11}$

These policies, however, have rarely been assessed by gender. ${ }^{8}$ As a result, there is little insight into how pricing, availability and marketing policies affect women and men separately. ${ }^{8}$ Understanding the impact by gender is likely to become more important as consumption patterns and burdens of disease change.

Although some provinces and territories have implemented policies that affect the price and availability of alcohol in the past few decades, ${ }^{12}$ the Government of Ontario has begun substantial policy changes - which have been widely reported - including reducing price minimums on beer, allowing bars and retail outlets to start selling alcohol in the early morning, announcing plans to permit the sale of beer in corner stores and cutting several social programs. The additional harms of such policies will likely be substantial. ${ }^{2}$

So, what can be done? According to a report from the Independent Scientific Committee on Drugs in the UK, MDMA (ecstasy), LSD and khat would all be much safer choices to accompany our social rituals, celebrations and everyday Canadian life; ${ }^{3}$ however, alcohol is the substance most adults use, and prohibiting it is not a solution. Instead, the federal and provincial governments should employ a public health approach to maximize benefits and minimize harms. Alcohol should be available for sale only within licensed and strictly monitored facilities with limited hours. Taxes and price minimums should be used to reduce alcohol-related harms. The increase in tax revenues could be used to fund essential provincial programs.

Ideally, governments should also ban all promotion of alcohol use, including marketing, branding and sponsorship of events. At minimum, governments should consider applying the rules it uses for tobacco promotion to alcohol. There is no reason to treat alcohol - a substance at least as harmful ${ }^{3}$ - differently. Furthermore, all policy and public health interventions should consider gender during planning, implementation and assessment to address the high burden of disease in men and the dramatic rise in alcohol-related harms in women.

\section{References}

1. Myran DT, Hsu AT, Smith G, et al. Rates of emergency department visits attributable to alcohol use in Ontario from 2003 to 2016: a retrospective populationlevel study. CMAJ 2019;191:E804-10.

2. The Chief Public Health Officer's report on the state of public health in Canada, 2015: alcohol consumption in Canada. Ottawa: Public Health Agency of Canada; 2016. Available: www.canada.ca/en/public-health/services/publications/chief-public -health-officer-reports-state-public-health-canada/2015-alcohol-consumption -canada.html (accessed 2019 June 12).

3. Nutt DJ, King LA, Phillips LD. Drug harms in the UK: a multicriteria decision analysis. Lancet 2010;376:1558-65.

4. Canadian Substance Use Costs and Harms Scientific Working Group. Canadian substance use costs and harms (2007-2014). Ottawa: Canadian Centre on Substance Use and Addiction; 2018.

5. Canadian Tobacco, Alcohol and Drugs (CTADS) Survey: 2017 detailed tables. Ottawa: Health Canada; modified 2019 Jan. 4. Available: www.canada.ca/en/ health-canada/services/canadian-tobacco-alcohol-drugs-survey/2017-summary /2017-detailed-tables.html\#t17 (accessed 2019 June 27).

6. Bulloch AGM, Williams JVA, Lavorato DH, et al. Trends in binge drinking in Canada from 1996 to 2013: a repeated cross-sectional analysis. CMAJ Open 2016;4: E599-604.

7. Slade T, Chapman C, Swift W, et al. Birth cohort trends in the global epidemiology of alcohol use and alcohol-related harms in men and women: systematic review and metaregression. BMJ Open 2016;6:e011827.

8. Fitzgerald N, Angus K, Emslie C, et al. Gender differences in the impact of population-level alcohol policy interventions: evidence synthesis of systematic reviews. Addiction 2016;111:1735-47.

9. Boniface S, Scannell JW, Marlow S. Evidence for the effectiveness of minimum pricing of alcohol: a systematic review and assessment using the Bradford Hill criteria for causality. BMJ Open 2017;7:e013497.

10. Hill-McManus D, Brennan A, Stockwell T, et al. Model-based appraisal of alcohol minimum pricing in Ontario and British Columbia: a Canadian adaptation of the Sheffield Alcohol Policy Model Version 2. Sheffield (UK): ScHARR, University of Sheffield; 2012. Available: https://dspace.library.uvic.ca//handle/1828/4792 (accessed 2019 June 26).

11. Alcohol and inequities: guidance for addressing inequities in alcohol-related harm. Copenhagen: World Health Organization; 2014. Available: www.euro. who.int/_data/assets/pdf_file/0003/247629/Alcohol-and-Inequities.pdf (accessed 2019 June 25).

12. Stockwell T, Wettlaufer A, Vallance K, et al. Strategies to reduce alcohol-related harms and costs in Canada: a review of provincial and territorial policies. Victoria: Canadian Institute for Substance Use Research, University of Victoria; 2019.

\section{Competing interests: None declared.}

This article was solicited and has not been peer reviewed.

Affiliation: Department of Family and Community Medicine, Women's College Hospital, Toronto, Ont.

Funding: Sheryl Spithoff is supported by a New Investigator award from the Department of Family and Community Medicine at the University of Toronto.

Acknowledgements: The author thanks Colin Mackenzie and Norman Giesbrecht for providing feedback on a draft of the commentary.

Correspondence to: Sheryl Spithoff, sheryl.spithoff@wchospital.ca 